\title{
XIV. Laws governing the decomposition of equivalent solutions of iodides under the influence of actinism
}

\section{Albert R. Leeds Ph.D.}

To cite this article: Albert R. Leeds Ph.D. (1880) XIV. Laws governing the decomposition of equivalent solutions of iodides under the influence of actinism, Philosophical Magazine Series 5, 10:60, 89-97, DOI: 10.1080/14786448008626895

To link to this article: http://dx.doi.org/10.1080/14786448008626895

冓 Published online: 28 Apr 2009.

Submit your article to this journal $[\pi$

Џll Article views: 2

Q View related articles $\longleftarrow$ 
side of the square has to be taken equal to ${ }_{2}^{5}$ wave-lengths, and in the second the height of the triangle as equal to $\frac{9}{2}$ wavelengths. The two expressions for the wave-velocity become $\frac{2}{5} \times 1 \frac{1}{2} \times 92$, and $\frac{2}{9} \times 1 \times 152$, both of which expressions are equal to $33 \frac{3}{4}$. Hence we are perhaps justified in inferring that the edges are stationary, and that the wave-velocity in the soap-film is nearly 34 inches in a second.

XIV. Laws governing the Decomposition of Equivalent Solutions of Iodides under the Influence of Actinism. By ALBERT R. LEEDS, Ph.D.*

TN a paper published in the Philosophical Magazine for June 1879 , I have given a brief review of the controversy as to whether potassium iodide, in a very dilute solution, is decomposable by sulphuric acid. I likewise pointed out, that the explanation of the opposite views entertained by experimenters upon this question was due to their having overlooked the essential part played by air or oxygen in the reaction. This last was brought to view by Baumert†, in the course of experiments by which he showed that Andrewsł, in the famous investigation undertaken to prove that Baumert's hypothesis that electrolytic ozone is a teroxide of hydrogen $\S$, was false, had himself fallen into an error. For Baumert showed that when a stream of electrolytic ozone has been deprived of all its active oxygen by passing through a neutral solution of iodide of potassium, it may bring about a liberation of iodine in an acidified solution, placed later in the series, many times greater (from 4 to 10 in the experiments tried) than that effected by the ozone itself in the first instance. So the curious fact remains, that while Andrews's main conclusion is true, all the results by which he succeeded in establishing it are affected by a constant error, and are in excess of their true values. The triumph of Andrews's opinion (1856) that ozone contains no hydrogen whatsoever, but in its substance-matter is identical with the matter of ordinary oxygen, probably explains why the permanently valuable part of Baumert's work has generally been lost sight of, and why the erroneous method of titrating ozone with an acidified solution of potassium iodide has been persisted in even down to the present day. Ten years after the facts above stated were made known by

* Communicated by the Author.

† Pogg. Ann. xcix. p. 88.

I Proc. Roy. Soc. vii. p. 475; Pogg. Ann. xcriii. p. 435.

\$ Phil. Mag. vi. p. 51; Pogg. Ann. lxxxix. p. 38.

Plil. Mag. S. 5. Vol. 10. No. 60. Aug. 1880. 
Baumert, they were rediscovered by Payen ", who extended their application to the action of nitric, acetic, oxalic, and other acids upon dilute solutions of potassium iodide, in and out of contact with the air.

In former paperst, a summary of which is given in the Philosophical Magazine (loc. cit.), I have shown that the presence of oxygen not merely facilitates, but is absolutely essential to, the occurrence of the reactions in all cases, and whether the reaction occurs in open or closed vessels, in the heat or cold, in darkness or in light. The only exception to this law is the case of an acid like nitric, which under the influence of light (the action of heat alone in the absence of light is being investigated) spontaneouslybreaks up, and supplies by internal change the essential oxygen. The experiments made to determine the rates of decomposition when various iodides in the presence of different acids were submitted to the influence of magnesium, electric, and solar rays, were made with solutions of known though not of chemically equivalent strength. To supply this defect a new series of experiments were performed immediately after the publication of those cited above; and it is to make known certain remarkable laws of actinochemical change deduced from these latter experiments that the present article is written.

The solutions were of such strength that 1 cubic centim. of each of the acids employed was chemically equivalent to $12 \cdot 6$ cubic centims. of a normal caustic soda solution; the iodides were each exactly equivalent to the 20-per-cent. solution of the potassium iodide. 1 cubic centim. of the iodide and 1 cubic centim. of the acid were used in each trial, the volume of the test being made up to 100 cubic centims. by the addition of distilled water. The tests were contained in "comparison-tubes" made of thin perfectly colourless glass, of uniform bore and dimensions, which were supported on frames in such a manner that each tube should be normal to the incident rays, and, in the case of magnesium and electric lamps, 6 inches from the focus of the light.

The first set of trials was made to determine whether the addition of starch as an indicator facilitated the decomposition under the influence of light, as had been originally supposed, or whether, as later on there had been reason to think, it retarded the reaction. In this, as in succeeding experiments, the amounts of iodine liberated are given in milligrams.

* Comptes Rendus, 1xii.p. 254.

† Proc. Amer. Chem. Soc. 1878, ii. no. 4 ; Journ. Amer. Chem. Soc. 1879 , i. p. 18 ; ibid. p. 65 . 
Effect of Starch on the Rate of Change (March 18, 1879). Brilliant Sun.

$$
\text { 1.30-2.30 P.M. } 2.30-3.30 . \quad 3.30-4.30 \text {. }
$$

Reagents. $\quad \begin{aligned} & 5 \text { cub. centims. } \\ & \text { starch-water. }\end{aligned} \quad \begin{gathered}30 \text { cub. centims. } \\ \text { starch. }\end{gathered}$ No starch.

\begin{tabular}{|c|c|c|c|}
\hline $\mathrm{H}_{2} \mathrm{SO}_{4}+\mathrm{KI}$ & . 0.48 & 0.51 & $1 \cdot 6$ \\
\hline $\mathrm{HCl}+$ & . $1 \cdot 18$ & $1 \cdot 46$ & $3 \cdot 5$ \\
\hline $\mathrm{HNO}_{3}+$ & . . $3 \cdot 10$ & $2 \cdot 57$ & $3 \cdot 5$ \\
\hline $\mathrm{H}_{2} \mathrm{SO}_{4}+\mathrm{CdI}_{2}$ & . $\quad 0.49$ & 0.82 & $1 \cdot 6$ \\
\hline $\mathrm{HCl}+"$ & - . $1 \cdot 90$ & $1 \cdot 11$ & $3 \cdot 5$ \\
\hline $\mathrm{HNO}_{3}+$ & . $2 \cdot 80$ & $2 \cdot 83$ & $3 \cdot 4$ \\
\hline $\mathrm{H}_{2} \mathrm{SO}_{4}+\mathrm{LiI}$ & . . 0.34 & 0.40 & $0 \cdot 3$ \\
\hline $\mathrm{HCl}+$ & 0.59 & 0.72 & $1 \cdot 7$ \\
\hline $\mathrm{HNO}_{3}+$ & $2 \cdot 7$ & $3 \cdot 86$ & $2 \cdot 7$ \\
\hline & 0.48 & & \\
\hline
\end{tabular}

March 19. 12 (noon)-1 P.M. Feeble Sunlight.

\begin{tabular}{|c|c|c|c|}
\hline $\mathrm{H}_{2} \mathrm{SO}_{4}+\mathrm{KI}$ & . & . 0.26 & $\ldots$ \\
\hline $\mathrm{HCl}+$ & . & . $0 \cdot 40$ & ... \\
\hline $\mathrm{H}_{2} \mathrm{SO}_{4}+\mathrm{CdI}_{2}$ & . & 0.22 & \\
\hline $\mathrm{HCl}+$ & $\theta^{\circ}$ & - 0.40 & \\
\hline $\mathrm{O}_{4}+\mathrm{LiI}$ & - & $\cdot \quad 0.20$ & \\
\hline
\end{tabular}

The experiments of March 18, performed as they were with a sun approaching the horizon, having been less decisive than could have been desired, they were repeated on the following day, but with the disadvantage of a feeble sunlight, with the result of showing that six times more iodine was set free in the absence than in the presence of starch. The suspended precipitate of starch iodide cut off the light, except upon the superficies of the solution. Henceforth the employment of starch was abandoned.

The next set of trials was instituted in order to observe the influence, upon the rate of change, of larger access of oxygen than that derivable from the air already dissolved, or in contact with the solution at its upper surface. To this end tests were prepared in duplicate; and through one pair of these duplicate solutions, the comparison-tubes being connected together in the manner of wash-bottles, a slow current of oxygen was passed. 
Influence of increased Supply of Oxygen. March 19, 1879. 11 A.M.-12. Feeble Sunlight.

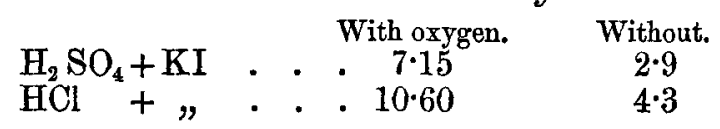

Also with Nitric Acid. 1-2 P.M. Snowing at time.

$$
\begin{aligned}
& \mathrm{H}_{2} \mathrm{SO}_{4}+\mathrm{KI} \text {. } . \quad 5 \cdot 25 \quad 1 \cdot 5 \\
& \mathrm{HNO}_{3}+, \text {. . . } 6.75 \quad 2.5
\end{aligned}
$$

The absorption of oxygen when sulphuric and hydrochloric acids are employed is expressed by the equations

and

(1) $4 \mathrm{KI}+2 \mathrm{H}_{2} \mathrm{SO}_{4}+\mathrm{O}_{2}=2 \mathrm{~K}_{2} \mathrm{SO}_{4}+2 \mathrm{H}_{2} \mathrm{O}+2 \mathrm{I}_{2}$,

(2) $4 \mathrm{KI}+4 \mathrm{HCl}+\mathrm{O}_{2}=4 \mathrm{KCl}+2 \mathrm{H}_{2} \mathrm{O}+2 \mathrm{I}_{2}$.

And since 100 cubic centims. of water, when saturated with air under the ordinary circumstances of temperature and pressure, would hold in solution only about $1 \mathrm{mgrm}$. of oxygen, the maximum amount of iodine which could be liberated during one of these tests, in case no fresh absorption of oxygen took place from the upper surface, would be $\cdot 16 \mathrm{mgrm}$. The influence of these conditions upon the accuracy of the estimations made with the iodo-acid actinometers is being submitted to further investigation.

In the case of nitric acid the reactions become much more complicated. For, in the first place, of the three mineral acids, nitric is the only one which spontaneously decomposes when subjected to sunlight in closed vessels. This is true both of the concentrated acids and when diluted with 500 times their volume of water. Moreover, in the latter case the presence of starch had no influence except in the nitric acid, in which it nearly doubled the rate of decomposition. The same effect of starch (whether it is true of organic matter in general has not been determined) is to be noted in the above table of decompositions for March 18, in which it will be seen that in the trials where starch was present the amounts of iodine liberated by nitric acid were largely in excess of those set free by equivalent amounts of other acids. In fine, while nitric acid conforms to the general law of actinic change, as expressed by the equation

$$
4 \mathrm{KI}+4 \mathrm{HNO}_{3}+\mathrm{O}_{2}=4 \mathrm{KNO}_{3}+2 \mathrm{H}_{2} \mathrm{O}+2 \mathrm{I}_{2},
$$

it is likewise subject to the special decomposition

$$
4 \mathrm{HNO}_{3} \text { (in sunlight) }=2 \mathrm{~N}_{2} \mathrm{O}_{4}+2 \mathrm{H}_{2} \mathrm{O}+\mathrm{O}_{2} \text {. }
$$

For these reasons, at an early stage of the inquiry, the actino- 
metric use of nitric acid was discontinued until the exact influence of temperature, actinism, oxygen, and organic matter upon its special rate of change had been established, and the nature of the accompanying reactions*.

In order to study the influence of mineral acids, trials were made as above, the solutions being of such strength that 1 c.c. of each was chemically equivalent to the same amount of mineral acid.

Effect of Organic Acids. March 20. 10.10 A.M. to 1.10 P.M. Good Sunlight.

Oxalic acid + potassium iodide $=6.5$ mgrms. $I$.

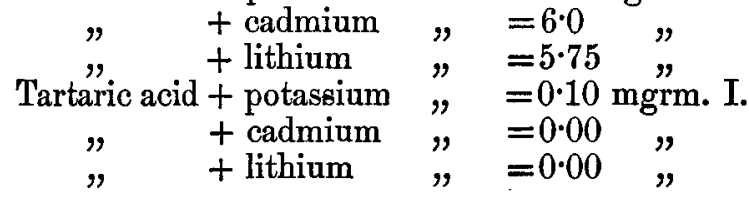

Nor any change with acetic acid during this three-hour interval. To determine more precisely the rate of change effected by the organic as compared with the mineral acids, it will be necessary to make simultaneous estimations; but even with oxalic acid, the most active of them all, it is evident that the amount of decomposition was relatively small.

An actinometric measurement of the solar ray was made with the equivalent solutions of various iodides and acids-the principal object being to note the effect upon the rate of decomposition of different acids in the presence of the same base, and of different basic radicals of the iodides in the presence of the same acid. The sunlight, which was good during the early part of the day, declined towards noon; and shortly afterwards the sky became overcast.

Actinometric Measurement of the Solar Ray. March 26, 1879.

\begin{tabular}{|c|c|c|c|c|c|c|c|c|c|c|}
\hline & $\begin{array}{c}9.30- \\
10_{\mathrm{A}, \mathrm{M}}\end{array}$ & $10-$ & $\begin{array}{l}10.30 \\
-11 .\end{array}$ & $\mid$\begin{tabular}{c|}
11 \\
11.30
\end{tabular} & $\begin{array}{l}11.30 \\
-12 .\end{array}$ & $\begin{array}{c}12- \\
12.30\end{array}$ & $\begin{array}{c}12.30 \\
-1 .\end{array}$ & $1-$ & Means. & Ratios. \\
\hline $\begin{array}{l}\mathrm{H}_{2} \mathrm{SO}_{4}+\mathrm{KI} . . \\
\mathrm{HCl}+\mathrm{KI} . . \\
\mathrm{H}_{2} \mathrm{SO}_{4}+\mathrm{CdI} . . \\
\mathrm{HCl}+\mathrm{CdI} . \\
\mathrm{H}_{2} \mathrm{SO}_{4}+\mathrm{LiI} . . \\
\mathrm{HCl}+\mathrm{LiI} . .\end{array}$ & $\begin{array}{l}1 \cdot 55 \\
2 \cdot 4 \\
1 \cdot 5 \\
2 \cdot 4 \\
1 \cdot 18 \\
1 \cdot 83\end{array}$ & $\begin{array}{l}1 \cdot 81 \\
2 \cdot 6 \\
1 \cdot 62 \\
2 \cdot 35 \\
1 \cdot 28 \\
1 \cdot 9\end{array}$ & $\begin{array}{l}2 \cdot 1 \\
2 \cdot 75 \\
1 \cdot 81 \\
2 \cdot 63 \\
1 \cdot 41 \\
2 \cdot 03\end{array}$ & $\begin{array}{l}2 \cdot 06 \\
2 \cdot 66 \\
1 \cdot 81 \\
2 \cdot 68 \\
1 \cdot 35 \\
2 \cdot 0\end{array}$ & $\begin{array}{l}1 \cdot 87 \\
2 \cdot 39 \\
1 \cdot 56 \\
2 \cdot 09 \\
1 \cdot 13 \\
1 \cdot 56\end{array}$ & $\begin{array}{l}1 \cdot 7 \\
2 \cdot 15 \\
1 \cdot 29 \\
1 \cdot 79 \\
0 \cdot 96 \\
1 \cdot 25\end{array}$ & $\begin{array}{l}1 \cdot 6 \\
2 \cdot 05 \\
1 \cdot 19 \\
1 \cdot 79 \\
0.93 \\
1 \cdot 58\end{array}$ & \begin{tabular}{|l|}
$0 \cdot 75$ \\
$2 \cdot 0$ \\
$1 \cdot 18$ \\
$1 \cdot 75$ \\
0.93 \\
$1 \cdot 4$
\end{tabular} & $\begin{array}{l}1 \cdot 68 \\
2 \cdot 5 \\
1 \cdot 49 \\
2 \cdot 18 \\
1 \cdot 15 \\
1 \cdot 69\end{array}$ & $\begin{array}{c}\mathrm{H}_{2} \mathrm{SO}_{4}: \mathrm{HCl} \\
1: 1: 48 \\
\mathrm{H}_{2} \mathrm{SO}_{4}: \mathrm{HCl} \\
1: 1 \cdot 46 \\
\mathrm{H}_{2} \mathrm{SO}_{4}: \mathrm{HCl} \\
1: 1 \cdot 47\end{array}$ \\
\hline
\end{tabular}

* Gay-Lussac states (Ann. de Chim. et de Phys. 1816, p. 317) that no decomposition of dilute acid takes place in the light, except in the presence of a certain quantity of concentrated sulphuric acid; also that the decomposition is into nitrous acid. 
94 Dr. A. R. Leeds on the Decomposition of Equivalent

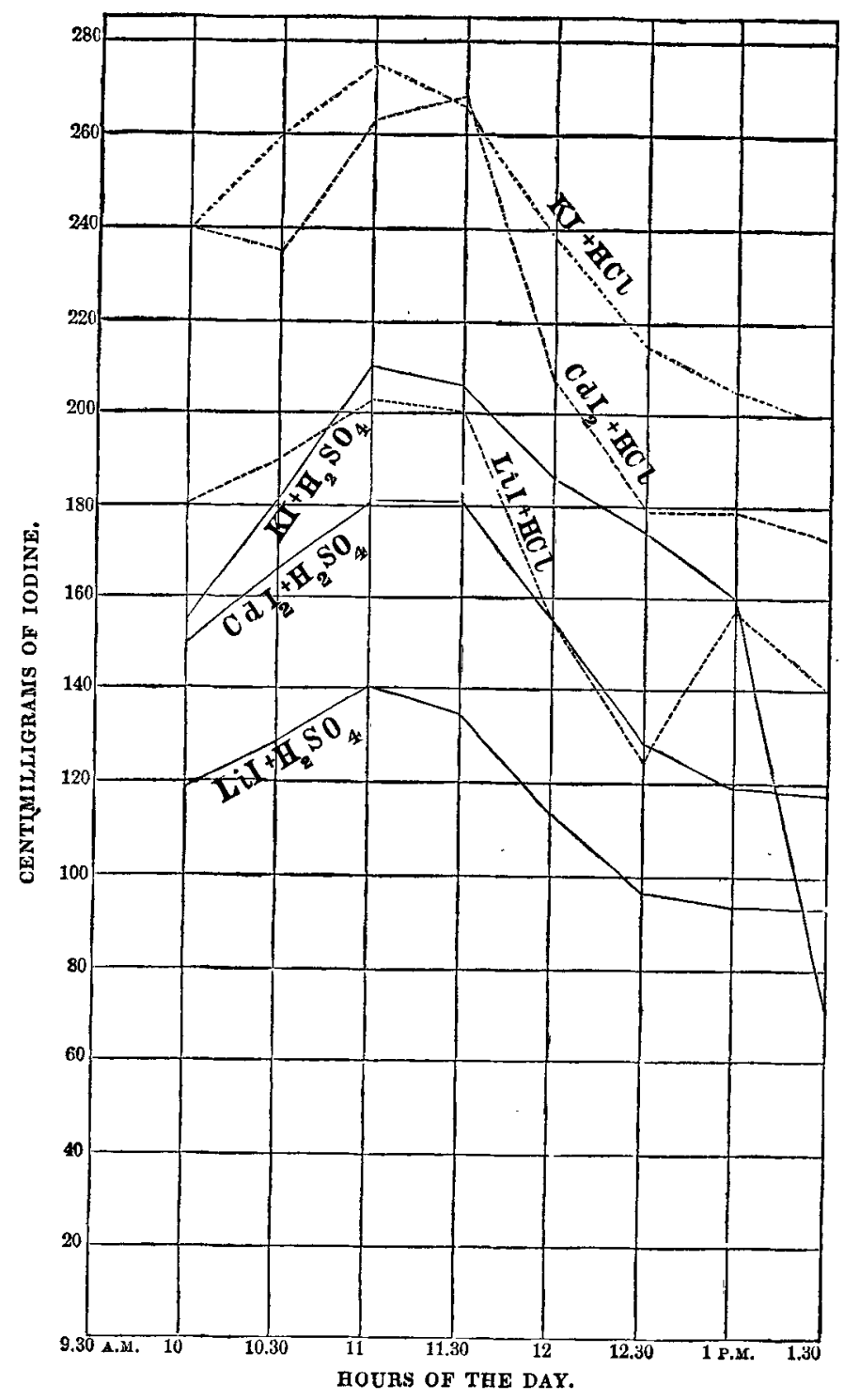


On comparison of the arithmetical means of the results obtained in fifty-four trials during the course of the same day, the striking fact is brought out that the amounts of iodine liberated by the two acids in the presence of the same base stand in a constant ratio to one another. The law of actinic force herein indicated may provisionally be expressed by the formula-The chemism of the chlorine radical is to that of the $\frac{1}{2} \mathrm{SO}_{4}$ radical (measured by the relative amounts of iodine liberated by each respectively in solutions of the metallic iodides exposed to the sunlight) as $1.47: 1$. There is no reason for inferring from the experiments that a similar definite ratio exists between the amounts of iodine liberated from different soluble iodides in the presence of the same acid.

\section{Comparison of the Actinic Intensities of the Solar, Electric, and Magnesium light.}

In making this comparison, the amounts of iodine liberated at the hour of maximum actinic intensity (1-1.30 P.M.) were taken in the case of the sun. The electric light was that emanating from a lamp of 7000 candle-power falling upon the solutions at a distance of six inches; the magnesium light, that derived from the burning of a single ribbon in the ordinary lamp placed at the same distance. The time of exposure to the electric light was 10 minutes, to the magnesium light 25 minutes, to the sun $\frac{1}{2}$ an hour; in the table all are calculated to one hour.

\begin{tabular}{|c|c|c|c|c|}
\hline $\mathbf{K}$ & & $\begin{array}{l}\text { Solar. } \\
2 \cdot 70\end{array}$ & $\begin{array}{c}\text { Electric. } \\
10^{\circ} 0\end{array}$ & $\begin{array}{c}\text { Magnesium. } \\
0.084\end{array}$ \\
\hline $\mathrm{HCl}$ & & $4 \cdot 00$ & $24 \cdot 0$ & 0.87 \\
\hline $\mathrm{H}_{2} \mathrm{SO}_{4}+\mathrm{CdI}_{2}$ & - & $2 \cdot 04$ & $9 \cdot 5$ & 0.072 \\
\hline $\mathrm{HCl}+$, & - & $3 \cdot 00$ & $24 \cdot 0$ & 0.6 \\
\hline${ }_{4}+\mathrm{LiI}$ & $\cdot$ & $1 \cdot 44$ & $5 \cdot 0$ & none \\
\hline & . & $2 \cdot 40$ & $15 \cdot 0$ & 0.3 \\
\hline
\end{tabular}

On examining this table, and still more readily the graphical illustration accompanying it, two phenomena become forcibly manifest:-

1st. The very much greater actinic intensity of the electric as compared with the solar ray, when compared in the manner indicated, and the very much less intensity of the magnesium. In order to bring the magnesium curve into the same diagram as the others, the numbers in the magnesium column were all multiplied by 10 . 


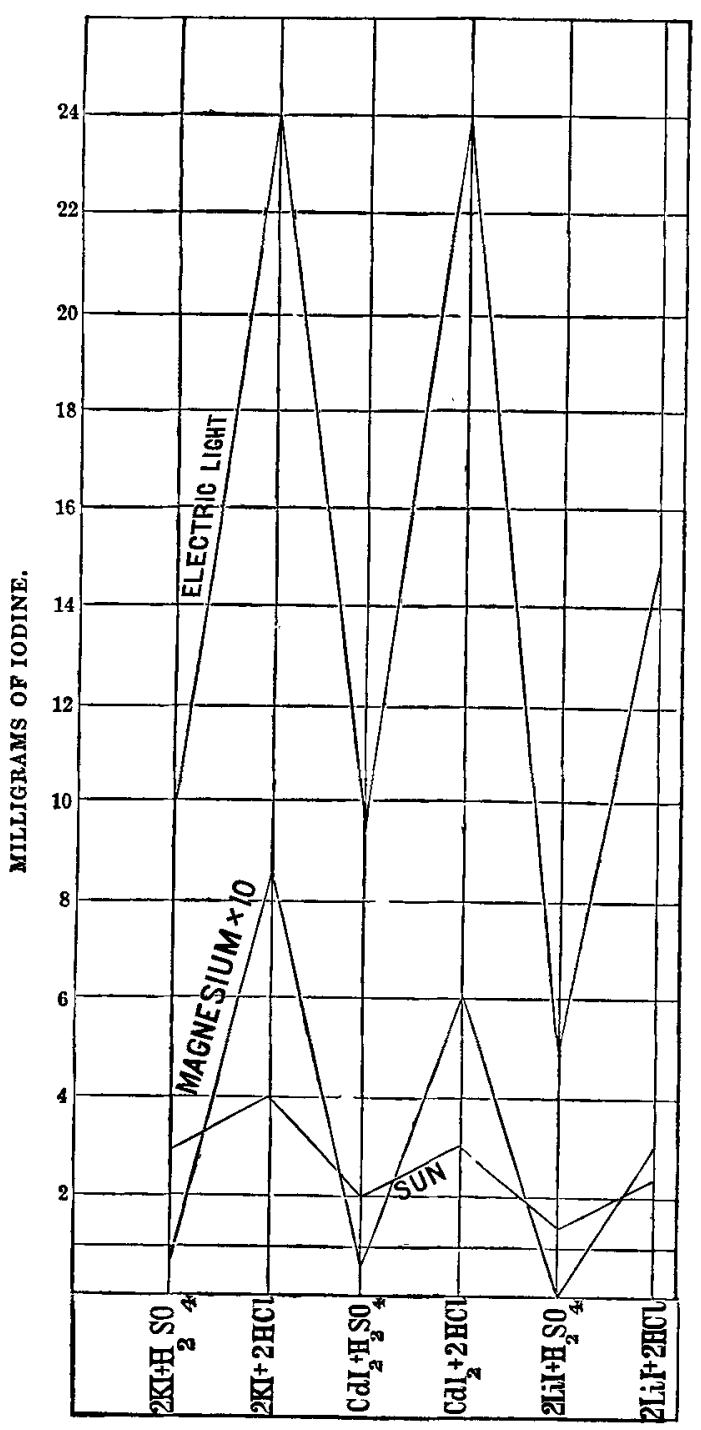


2nd. Instead of the relative chemism of the chlorine atom, as estimated by its iodine-liberating power under these conditions, being 1:5 in all three cases, it is 6 with the electric and 10 with the magnesium light. The examination of these differences, as related to the actinic forces of different sources of light and to different acid and basic radicals, is being investigated further.

Finally, the influence of absorbing media upon the invisible rays of the sun and electric light were determinedthe comparison-tubes being surrounded by a thickness of 3 cubic metres of ammonio-sulphate of copper, neutral potassium, chromate, and fuchsine, each solution being brought to the apparent degree of translucency for the blue, yellow, and red respectively. The exposure to the sun was from 9.30 A.M. to 5.30 P.M., to the electric light 20 minutes; but both are reduced to the interval of 1 hour.

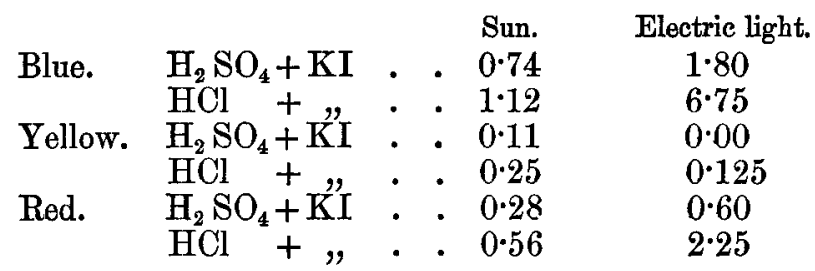

These figures show that the selective action of absorbing media upon the invisible rays of different illuminants varies greatly, and suggests the employment of this method for the mapping out of absorption-spectra for the actinic portion.

Stevens Institute of Technology, June 1880.

\section{Vortex Statics. By Sir William Thomson*.}

$T$ HE subject of this paper is steady motion of vortices. 1 1. Extended definition of "steady motion." The motion of any system of solid or fluid or solid and fluid matter is said to be steady when its configuration remains equal and similar, and the velocities of homologous particles equal, however the configuration may move in space, and however distant individual material particles may at one time be from the points homologous to their positions at another time.

2. Examples of steady and not steady motion :-

(1) A rigid body symmetrical round an axis, set to rotate round any axis through its centre of gravity, and left free,

* From the Proceedings of the Royal Society of Edinburgh, Session 1875-76. Communicated by the Author. 